\title{
Bacterial Diversity Evolution in Maya Plaster and Stone Following a Bio-Conservation Treatment
}

\author{
Fadwa Jroundi ${ }^{1 *}$, Kerstin Elert ${ }^{2}$, Encarnación Ruiz-Agudoº, \\ María Teresa Gonzalez-Muñoz ${ }^{1}$ and Carlos Rodriguez-Navarro ${ }^{2}$ \\ ${ }^{1}$ Department of Microbiology, University of Granada, Granada, Spain, ${ }^{2}$ Department of Mineralogy and Petrology, University \\ of Granada, Granada, Spain
}

OPEN ACCESS

Edited by:

Fernando Poyatos-Jimenez, University of Seville, Spain

Reviewed by: Zeynep Basaran Bundur, Özyeğin University, Turkey Rodorico Giorgi, Consorzio Interuniversitario Per Lo Sviluppo Dei Sistemi A Grande Interfase, Italy

Guadalupe Pinar

University of Natural Resources and Life Sciences Vienna, Austria Julio Romero-Noguera

Seville University, Spain

*Correspondence: Fadwa Jround fadwa@ugr.es;

fadwajroundi@gmail.com

Specialty section: This article was submitted to

Microbiotechnology, a section of the journa

Frontiers in Microbiology

Received: 26 August 2020 Accepted: 19 October 2020 Published: 09 November 2020

Citation Jroundi F, Elert K, Ruiz-Agudo E, Gonzalez-Muñoz MT and Rodriguez-Navarro C (2020) Bacterial

Diversity Evolution in Maya Plaster and Stone Following

a Bio-Conservation Treatment.

Front. Microbiol. 11:599144. doi: 10.3389/fmicb.2020.599144
To overcome the limitations of traditional conservation treatments used for protection and consolidation of stone and lime mortars and plasters, mostly based on polymers or alkoxysilanes, a novel treatment based on the activation of indigenous carbonatogenic bacteria has been recently proposed and applied both in the laboratory and in situ. Despite very positive results, little is known regarding its effect on the evolution of the indigenous bacterial communities, specially under hot and humid tropical conditions where proliferation of microorganisms is favored, as it is the case of the Maya area. Here, we studied changes in bacterial diversity of severely degraded tuff stone and lime plaster at the archeological Maya site of Copan (Honduras) after treatment with the patented sterile M-3P nutritional solution. High-throughput sequencing by Illumina MiSeq technology shows significant changes in the bacterial population of the treated stones, enhancing the development of Arthrobacter, Micrococcaceae, Nocardioides, Fictibacillus, and Streptomyces, and, in one case, Rubrobacter (carved stone blocks at Structure 18). In the lime plaster, Arthrobacter, Fictibacillus, Bacillus, Agrococcus, and Microbacterium dominated after treatment. Most of these detected genera have been shown to promote calcium carbonate biomineralization, thus implying that the novel bio-conservation treatment would be effective. Remarkably, the treatment induced the reduction or complete disappearance of deleterious acid-producing bacteria such as Marmoricola or the phylum Acidobacteria. The outcome of this study demonstrates that such a bio-conservation treatment can safely and effectively be applied on temples, sculptures and stuccos of the Maya area and, likely, in other hot and humid environments.

Keywords: Maya area, bacterial diversity, bioconsolidation treatment, nutritional medium, carbonatogenic bacteria, tuff stone, plasters

\section{INTRODUCTION}

Stone and lime plaster deterioration is one of the most serious problems affecting historical structures and sculptures all over the world (Warscheid and Braams, 2000; Gil et al., 2015). Deterioration is due to physical, chemical, and biological weathering phenomena, acting alone or in combination, which frequently result in irreparable loss of priceless artworks. In aggressive tropical 
environments, characterized by heavy rainfalls, high temperatures and high relative humidity, typical for most Maya archeological sites in Mesoamerica, these phenomena are particularly harmful and enhance biodeterioration related to the impact of different (micro)organisms (Videla et al., 2000; Caneva et al., 2005). Biodeterioration intensity depends on the material, possible previous interventions, and environmental conditions that determine the extent and composition of the microbial communities colonizing the cultural artifacts (Valentín, 2010).

Microorganisms are able to cause several types of damage on monument surfaces, including biophysical, biochemical, and aesthetic biodeterioration, which may occur simultaneously or separately (see reviews by Warscheid and Braams, 2000; Valentín, 2010; Gil et al., 2015; Mihajlovski et al., 2017; Sterflinger et al., 2018). Although some microorganisms can cause biodeterioration, many of them can offer a very effective solution for the conservation of deteriorated historical sculpture and monuments.

The conservation of such historic and culturally important artworks typically involves the application of consolidating agents that in many cases do not provide long-lasting efficacy and induce further damage due to pore blocking as well as severe aesthetic alterations (Giorgi et al., 2010; Sassoni et al., 2011). Bacterial bioconsolidation has emerged in recent decades as an alternative to non-effective traditional consolidants. This environmentally friendly conservation treatment involves the consolidation of stone and plaster through bacterially induced calcium carbonate biomineralization (González-Muñoz et al., 2008). Bacterial biomineralization is a widespread phenomenon reported for many natural environments such as soils and caves (Boquet et al., 1973; Wright and Oren, 2005). This strategy is effective for the protection of stone or plaster artworks because it can form exceptionally strong hybrid organic-inorganic carbonate cements (Jroundi et al., 2017). One particularly effective strategy involves the application of a nutritional solution (M-3P) that selectively activates indigenous carbonatogenic bacteria present in the treated substrate (Rodriguez-Navarro et al., 2003, 2012, 2015; Ettenauer et al., 2011; Jroundi et al., 2012, 2017). In fact, the application of the patented M-3P nutritional solution containing amino acids (Bacto Casitone) and calcium, promotes the growth of the indigenous chemoorganotrophic bacteria that are able to use amino acids as a source of carbon, nitrogen, and energy. The bacterial metabolic activity involves the oxidative deamination of amino acids and the subsequent release of ammonia, which leads to the formation of $\mathrm{NH}_{4}{ }^{+}$and $\mathrm{OH}^{-}$ions and induces an increase in $\mathrm{pH}$. Under these alkaline conditions, dissolved $\mathrm{CO}_{2}$ (both atmospheric and metabolically derived $\mathrm{CO}_{2}$ ) transform into $\mathrm{CO}_{3}{ }^{2-}$ ions that react with $\mathrm{Ca}^{2+}$ (present in the M-3P medium), leading to the precipitation of calcium carbonate, once a sufficient supersaturation is reached (Rodriguez-Navarro et al., 2003, 2015; Jroundi et al., 2012).

The first step to understand the relationship between microorganisms and environment, as well as its potential response during a bio-conservation treatment, is to identify the bacteria present in the cultural artwork. Next generation sequencing approaches have been developed to study the complexity of microbial communities in a wide range of environments, allowing in-depth studies of environmental samples (Marvasi et al., 2019). Such sequencing technologies, in addition to other molecular approaches, have also been applied to analyze the diversity, composition and distribution of microbial communities dwelling on different historical objects (Zimmermann et al., 2006; Piñar et al., 2015; Mihajlovski et al., 2017; Adamiak et al., 2018; Li et al., 2016, 2018), all of them mainly focusing on the biodeteriorating role of these dwelling microorganisms. However, monitoring the evolution of such microbial communities, before and after the application of conservation treatments, is rarely reported in the literature. Here, we apply DNA extraction, PCR amplification and highthroughput sequencing and use bioinformatics and statistical analysis to characterize and compare bacterial colonization on historic Maya mortar and stone before and after a bioconsolidation treatment applied in the laboratory and in situ at the archeological site of Copan. Up to now, this bacterial conservation treatment based on the application of a sterile nutritional solution (M-3P) has only been applied in situ on monuments located in temperate, moderately humid-dry European environments (e.g., Spain and Portugal) (Jroundi et al., 2012, 2017; Rodriguez-Navarro et al., 2015; DelgadoRodrigues and Ferreira-Pinto, 2019). It is therefore unknown, whether such a treatment is effective and does not produce any deleterious side effects under extreme hot and humid environmental conditions typical for the Maya area, where the bacterial population is unknown and the potential for microbial biodeterioration is very high. The outcome of this study will be crucial for the evaluation of the effectiveness of bacteria-assisted consolidation treatments in tropical climates and lay the basis for the development of effective novel conservation strategies for the Maya area. The approach presented here will also be imperative for the understanding of natural biosystems and to determine the effect and efficiency of different conservation treatments (e.g., biocides and conventional organic consolidants, which could serve as a nutritional source for microorganisms). Furthermore, it could assist in the selection of appropriate measures (e.g., climate control) to limit/restrain the impact of deteriogenic communities on works of art, an important aspect in conservation and restoration practice. In summary, this study focuses on determining the impact of the biotreatment on the substrates' bacterial diversity as a means to gauge the applicability of this environmentally friendly bioconsolidation approach in tropical regions. In a parallel study we are currently evaluating the effectiveness of the treatment applied on these Maya stones and plaster by analyzing the formation of bacterial calcium carbonates and their impact on the physical-mechanical properties of the treated substrates.

\section{MATERIALS AND METHODS}

\section{Site Description}

This study was performed at the Maya site of Copan, Honduras (Figure 1), one of the most important centers of the Mayan civilization, which has been excavated since the 19th century and was designated a World Heritage Site by UNESCO in 1980. 

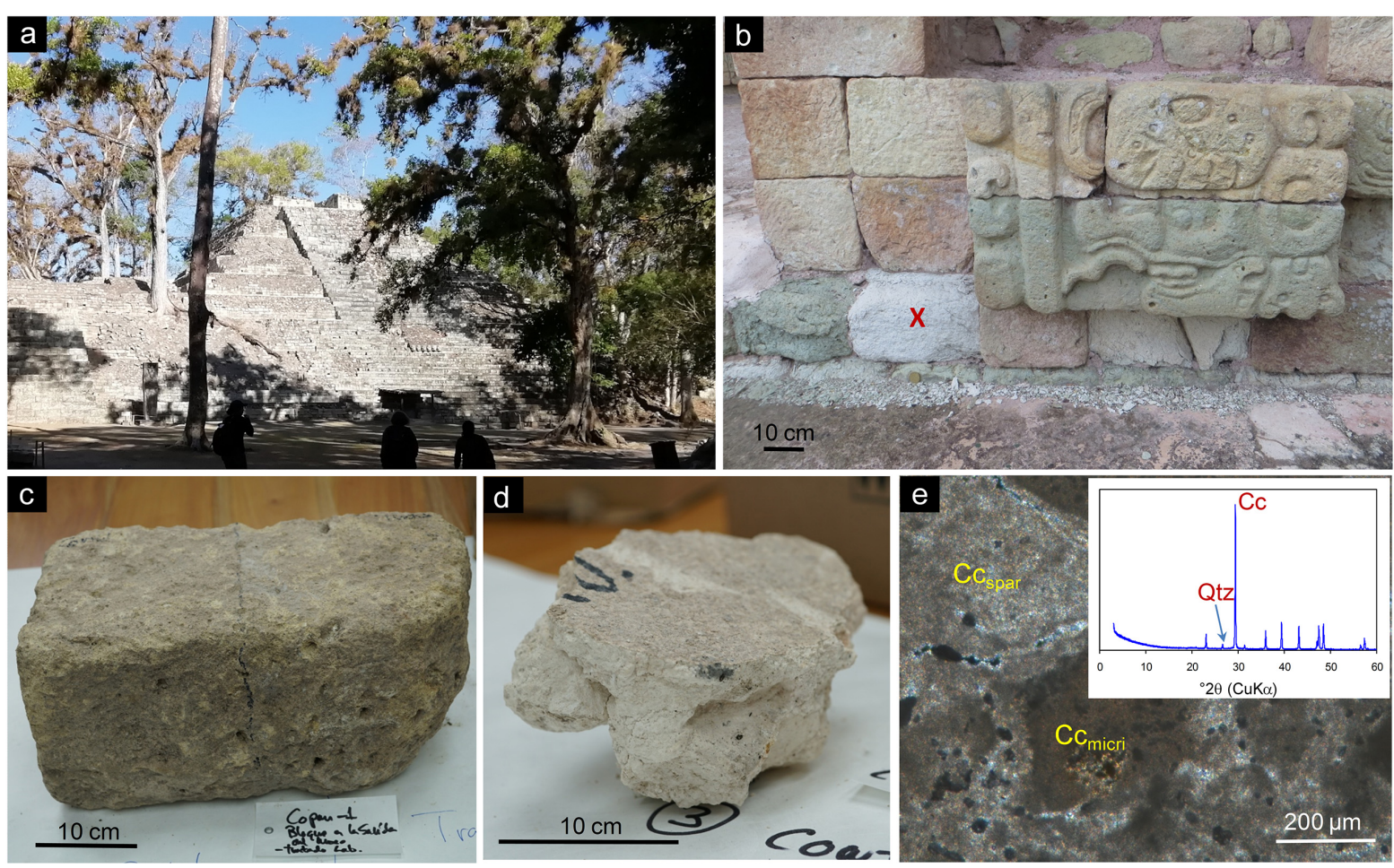

FIGURE 1 | The Maya site of Copan: (a) general overview of Copan's Acropolis; (b) stone blocks treated at Structure 18. The red x marks the treated stone block. Note the large amount of stone debris located at the bottom of the wall; (c) detail of the tuff stone treated at the LACEM laboratory; (d) picture of the plaster treated at the LACEM laboratory; (e) optical microscopy photomicrograph of the Maya plaster (crossed polarizer). Both micritic calcite (Cc $c_{\text {micri) }}$ and sparitic-microsparitic calcite ( $\mathrm{Cc}_{\text {spar }}$ ) are observed making up this (almost pure) lime plaster (no aggregate is visible in the images). The inset shows the X-ray diffraction pattern of the plaster. The main Bragg reflections of minerals present in the plaster are indicated (Cu Ka radiation). Cc, calcite; Qtz, quartz.

This archeological site represents one of the most spectacular achievements of the Classic Maya period (AD 420-820), involving a number of architectural and sculptural monuments constructed and extensively carved using a local volcanic tuff stone, and decorated with lime plaster (Fash, 1991). It is composed of complex ruins with several secondary complexes surrounding them, including the well-known Hieroglyphic Stairway, displaying the longest known Classic Maya inscription (Fash et al., 1992; Webster, 1999). The remains are not only endangered by physico-chemical and biological deteriorating agents, but also by the continued erosive action of the Copan river, current land use, and several restoration/conservation interventions (performed during the 20th century) involving the use of non-compatible materials such as Portland cement (Doehne et al., 2005). Copan is situated on the southeastern frontier of the Lowland Maya culture area; what is today western Honduras (latitude, $14^{\circ} 51^{\prime} 30^{\prime \prime} \mathrm{N}$, longitude, $89^{\circ} 9^{\prime} \mathrm{W}$ ) (Webster, 1999). The site is located at $\sim 700 \mathrm{~m}$ a.s.l., has an average annual $T$ of $\sim 26^{\circ} \mathrm{C}$ and precipitation averaging $\sim 2000-3000 \mathrm{~mm}$ annually (McVey, 1998). It is therefore considered a hot and humid tropical environment.

\section{Bioconsolidation Treatment}

For the testing of the bioconsolidation treatment based on the application of the patented M-3P nutritional solution, two types of substrates (tuff stone and lime plaster) were considered in this study:

(1) Stone block (sample CI) located in the base section of a vertical wall of a Late Classic Temple (Structure 18) made up of a buff-colored carved tuff stone, showing extensive deterioration and material loss due to scaling (Figure 1B). The treatment was applied in situ (see details below). The mineralogy and main weathering mechanisms of this volcanic tuff stone are reported in Doehne et al. (2005). The authors indicate that this rhyolitic tuff is relatively porous $(\sim 20 \%)$ and made up of a devitrified silicate glass matrix (made up of zeolites and clay minerals), with abundant phenocrystals of quartz and feldspars. It typically displays extensive flaking and scaling, resulting in continuous loss of stone and surface reliefs. Lost material tends to accumulate at the bottom of exposed walls, as can be seen in Figure 1B. The ultimate cause of such an advanced weathering is not clear, although it has been claimed that microbial biodeterioration and humidity play an important role (Caneva et al., 2005; Doehne et al., 2005).

(2) Decontextualized stone block (sample CPN) originally located on the ground next to the Copan Acropolis (Figure 1C). The stone was partially covered by soil and plant leaves. This buff colored tuff stone block was treated 
ex situ at the Laboratorio de Conservación de Escultura Maya (LACEM; Laboratory for the Conservation of Maya Sculpture), which is part of the Copan Sculpture Museum (located within the site premises).

(3) Block of Late Classic lime plaster floor (sample MC) from Structure 12 (AD 800). After excavation, it was stored at the Copan Sculpture Museum storage area. This plaster (Figure 1D) was treated ex situ at the LACEM. Preliminary mineralogical and petrographic analyses show that it is made up of calcite (binder) with a minor amount $(<5$ $w t \%$ ) of quartz (according to X-ray diffraction analysis performed on a X'Pert PRO, PANalytical diffractometer using a $\mathrm{CuK} \alpha$ source, $3-60{ }^{\circ} 2 \theta$ explored range and 0.01 ${ }^{\circ} 2 \theta /$ min goniometer speed) (see inset in Figure 1E). Under the polarized light petrographic microscope (Jenapol V), it shows a compact but highly porous structure made up of micritic and microsparitic calcite crystals (Figure 1E). Basically, it is a pure lime plaster with almost no aggregate.

Note that this biotreatment application was a trial aimed at gauging its potential effectiveness under the particular exposure conditions in this tropical region. In order to minimize possible negative side-effects in case of treatment failure (i.e., possible activation of harmful bacteria leading to substrate acidification or discoloration), we have restricted the extent of its application for minimum impact. The extent of the testing and sampling was further restricted taking into account the value and uniqueness of this Maya site. Therefore, the three selected substrates were chosen considering their representativeness regarding the different materials and exposure conditions at the site. The first substrate (stone at Structure 18) is representative of the Copan tuff stones of different structures at the Copan Acropolis; the decontextualized stone block is representative of the excavated stone blocks and sculptures currently located at the Copan Sculpture Museum and storage area; and the plaster is representative of interior lime plaster floors and walls in structures at the Copan Acropolis, as well as plaster pieces located at the Copan Sculpture Museum and storage area.

The treatment application procedure is described in detail in Jroundi et al. (2017). Briefly, it involves the application of the sterile M-3P solution which contains 1\% [wt./vol.] Bacto Casitone (a pancreatic digest of casein), 1\% [wt./vol.] $\mathrm{Ca}\left(\mathrm{CH}_{3}-\mathrm{COO}\right)_{2} \cdot 4 \mathrm{H}_{2} \mathrm{O}$ (total calcium: $43.44 \mathrm{mM}$ ), 0.2\% [wt./vol.] $\mathrm{K}_{2} \mathrm{CO}_{3} \cdot 1 / 2 \mathrm{H}_{2} \mathrm{O}$ (total potassium: $35.6 \mathrm{mM}$; total carbonate: $17.8 \mathrm{mM}$ ), and $10 \mathrm{mM}$ phosphate buffer in distilled water $(\mathrm{pH}=8)$ (Rodriguez-Navarro et al., 2015). The nutritional solution was sprayed onto the stone/plaster blocks until saturation, twice a day for six consecutive days. Areas were protected from light exposure with cardboards during treatment. The treatment was performed during the dry season (February) with outdoors $T$ ranging from 18 to $28^{\circ} \mathrm{C}$ and $\mathrm{RH}$ of $\sim 80 \pm 5 \%$. Note that the $T$ and relative humidity $(\mathrm{RH})$ within the LACEM during treatment was not controlled ( $\left.\sim 20-26^{\circ} \mathrm{C}, \sim 80 \pm 5 \% \mathrm{RH}\right)$, thus basically reflecting the outdoors conditions.
Both in situ and ex situ treatment applications where performed considering that future conservation interventions should be performed both in situ, on the different structures exposed outdoors at this Maya site (e.g., Hieroglyphic Stairway), as well as ex situ (indoors), on the vast collection of carved stone, sculptures, and plasters currently exhibited at the Copan Sculpture Museum as well as in the storage facilities. Once the treatment effectiveness is fully evaluated, a feasibility study for the scaling up of the treatment will be performed.

\section{DNA Extraction, PCR Amplification, and Sequencing}

Genomic DNA was extracted from solid samples collected aseptically (using sterile tweezers, and sterile Eppendorf tubes) from all three samples, both before treatment application (CI_CONT, CPN_CONT, and MC_CONT: taken at time 0 , before the application of $\mathrm{M}-3 \mathrm{P}$ nutritional solution) and 3 months after treatment application (CI_ TREATED, CPN_TREATED, and MC_TREATED). Three replicates of each sample were performed. After collection at the site, each sample/replicate $(\sim 0.5 \mathrm{~g})$ was aseptically placed in a 2 -mL sterile screw-cap tube containing glass beads. One $\mathrm{mL}$ of lysis buffer (100 mM Tris-HCl [pH 8.0], 100 mM EDTA [pH 8.0], $100 \mathrm{mM}$ $\mathrm{NaCl}, 1 \%$ polyvinylpyrrolidone [PVP], and 2\% SDS), $24 \mu \mathrm{L}$ freshly made lysozyme $(10 \mathrm{mg} / \mathrm{mL})$, and $2 \mu \mathrm{L}$ proteinase $\mathrm{K}$ $(20 \mathrm{mg} / \mathrm{mL})$ were added to each tube. The tubes were vigorously shaken for $2 \mathrm{~min}$ in vortex followed by mechanical lysis of the cells performed twice using a FastPrep ${ }^{\circledR}$ FP120 (at a speed of $5.5 \mathrm{~m} / \mathrm{s}$ for $45 \mathrm{~s}$ ) with intermittent cooling on ice for $5 \mathrm{~min}$. The tubes were incubated at $37^{\circ} \mathrm{C}$ for $30 \mathrm{~min}$ and then at $60^{\circ} \mathrm{C}$ for another $30 \mathrm{~min}$, and subsequently centrifuged at $14,000 \times g$ for $5 \mathrm{~min}$ at room $T$. The upper (aqueous) phase was mixed by gently inverting with one volume of phenol:chloroform:isoamyl alcohol (25:24:1, pH 8), and then centrifuged at $1,500 \times g$ for $10 \mathrm{~min}$ at $4^{\circ} \mathrm{C}$. The upper (aqueous) phase was washed with one volume of phenol:chloroform (1:1) and centrifuged under the same conditions. DNA was precipitated by adding 1/10 volume of sodium acetate ( $3 \mathrm{M}, \mathrm{pH}$ ) and one volume of isopropanol, incubating for $1 \mathrm{~h}$ at $-80^{\circ} \mathrm{C}$ and centrifuging for $30 \mathrm{~min}$ at $5,000 \times g$ at $4^{\circ} \mathrm{C}$. The obtained DNA was dissolved in Tris (5 nM, pH 8.5)-TE buffer (10 mM Tris- $\mathrm{HCl}[\mathrm{pH} 8.0]$ and $1 \mathrm{mM}$ EDTA) previously heated at $65^{\circ} \mathrm{C}$. Extracted DNAs were stored at $-20^{\circ} \mathrm{C}$ until all sample extractions were completed. The DNA concentrations were determined on Qubit 3.0 Fluorometer using the dsDNA HS (high sensitivity) assay kit (Jiang et al., 2015).

High-throughput amplicon sequencing using 250 bp pairedend sequencing chemistry (MiSeq Illumina) was performed. Total DNA of each sample was amplified targeting the hypervariable V3-V4 regions by using the $16 \mathrm{~S}$ rRNA gene primers $341 \mathrm{~F}$ and $785 \mathrm{R}$ (Klindworth et al., 2013). Illumina libraries were constructed and sequenced at LGC Genomics ${ }^{1}$, GMBH, Berlin, Germany. The resulting DNA libraries were pooled equimolarly and barcoded to be sequenced in one single Illumina lane.

\footnotetext{
${ }^{1}$ http://www.lgcgroup.com/
} 


\section{Bioinformatics and Statistical Analysis}

Demultiplexing of all libraries was carried out for each sequencing lane using the Illumina bcl2fastq. After quality controlling and combining using PandaSeq (Masella et al., 2012), paired-end reads were renamed using BESPOKE software (SeqSuite ${ }^{2}$ ) and then analyzed through the QIIME v1.8 pipeline (Caporaso et al., 2010). UCLUST and SILVA 119 QIIME 16S database were used to identify, classify and annotate operational taxonomic units (OTU). Explicet (2.10.5) was finally used to analyze clustered and annotated OTU. Rarefaction curves were determined using the Vegan v2.4-6 package in $\mathrm{R}$ v3.4.3 environment (data not shown).

Species richness was measured through the use of alphadiversity metrics (Chao1, Shannon diversity index, and observed species) in Explicet and $\mathrm{R}$ softwares. Beta-diversity, the similarity between the identities of taxa, and their abundances in each sample were assessed using Bray-Curtis distances (weighted UniFrac distances) measured in QIIME and PAST3 v. 3.18 and the output was visualized by means of principal coordinate analysis (PCoA). A heatmap was constructed for the visualization of specific differences in community composition using the heatmap.2 function in the $\mathrm{R}$ gplots v2.11.0 package on log-normalized abundance data. At the genus level, the heatmap included only taxa at $\geq 1.5 \%$ relative abundance in all samples/replicates. Relative abundance graphs were constructed representing relative microbial abundance averages of three biological replicates. Additionally, similarity of percentages analysis (SIMPER) was performed using PAST3 software. Network analyses were conducted in the $\mathrm{R}$ environment using the VEGAN package and only strong Pearson's correlations $(\rho>0.8$ or $\rho<-0.8)$ were considered. Network visualization and modularization were carried out on the interactive platform of Cytoscape (Shannon et al., 2003).

\section{Data Availability}

All raw sequences used in this study are available in the sequence read archive (SRA) at NCBI database under the SRA accession number PRJNA650538.

${ }^{2}$ http://bioware.soton.ac.uk

\section{RESULTS}

\section{Richness and Distribution of the Bacterial Communities}

A total of 910,782 bacterial $16 \mathrm{~S}$ rRNA gene sequences were recovered for all samples. They were distributed in a mean of 63,420 for CI_CONT, 40,835 for CI_TREATED, 46,518 for CPN_CONT, 219,251 for CPN_TREATED, 4,990 for MC_CONT, and 46,108 for MC_TREATED. These sequences were used for community analyses by QIIME and OTUs were assigned by clustering sequences with over $97 \%$ sequence identity. A number of 1,165 OTUs were identified, indicating high microbial diversity.

Alpha-diversity analysis revealed no significant differences in bacterial richness of the studied samples regardless of the metric used (Table 1). Chao1 richness estimator and observed species index (Sobs) indicated high and comparable bacterial richness in the communities of both stone and plaster samples. As seen in Table 1, the samples have many sequences, which were also confirmed by Shannon, Simpson and the Goods coverage indexes. The samples displayed high richness and had similar alpha-diversities. According to Simpson index, all taxa were distributed equally in the CI bacterial communities after treatment with an average ranging from 0.53 to 0.56 , whereas in the rest of the samples more than one taxon were dominating the communities with a Simpson index ranging from 0.89 to 0.98 .

Beta-diversity revealed significant differences in bacterial community structure and abundance between the studied samples before and after the M-3P treatment. The samples formed three distinct clusters, in accordance with the structure type, localization and substrate type, on the principal coordinate analysis $(\mathrm{PCoA}=$ multidimensional scaling, $\mathrm{MDS}$ ) plot of the bacterial community composition (using OTU abundance) of all tested samples (Figure 2). Consequently, the analysis of the $\mathrm{CI}, \mathrm{CPN}$, and $\mathrm{MC}$ samples indicated that they were clearly classified according to the type of substrate (mortar or tuff) and treatment application.

\section{Bacterial Community Composition and Structure}

Among the 30 phyla determined in all three samples, Actinobacteria, Firmicutes, Cyanobacteria, Proteobacteria,

TABLE 1 | Inference statistics at genus level of the different samples of the Maya archeological site.

\begin{tabular}{|c|c|c|c|c|c|c|c|c|}
\hline SAMPLES & Taxa_richness & Simpson_1-D & Shannon_H & Pielou's evenness & Fisher's Alpha & ACE & CHAO1 & Goods coverage index \\
\hline Cl_CONT & 1561 & 0.94 & 3.77 & 0.51 & 291.81 & 137.3 & 139.1 & 0.999 \\
\hline Cl_TREATED & 496 & 0.54 & 1.8 & 0.29 & 79.8 & 105.9 & 107.4 & 0.999 \\
\hline CPN_CONT & 2592 & 0.96 & 5.10 & 0.65 & 603.1 & 315.1 & 314.4 & 0.998 \\
\hline CPN_TREATED & 4619 & 0.91 & 3.61 & 0.43 & 850.1 & 219.6 & 223.1 & 0.998 \\
\hline MC_CONT & 239 & 0.98 & 4.65 & 0.85 & 47.9 & 85.3 & 85.9 & 0.998 \\
\hline MC_TREATED & 1108 & 0.93 & 3.67 & 0.53 & 211.2 & 141 & 138.1 & 0.999 \\
\hline
\end{tabular}

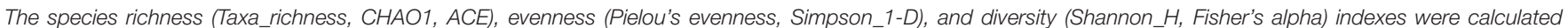

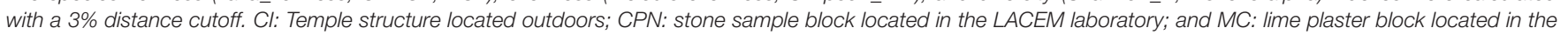
LACEM laboratory. 


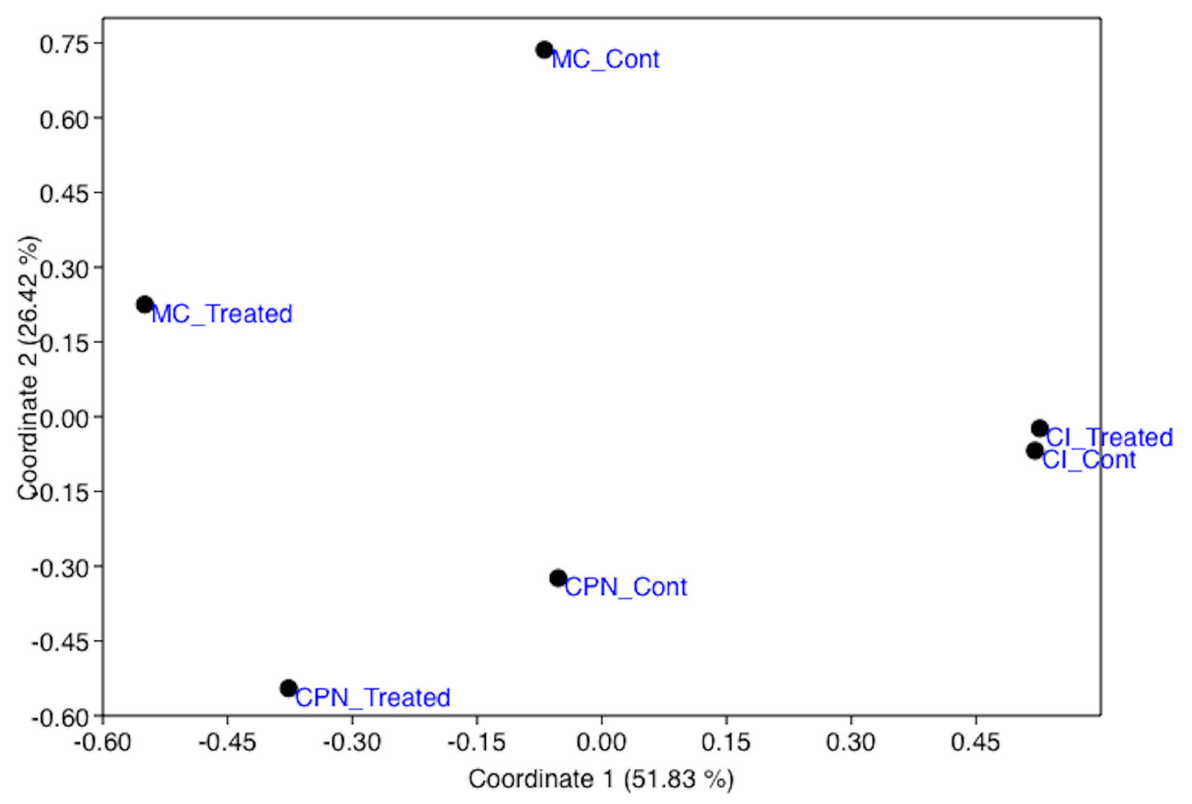

FIGURE 2 | Principal coordinates analysis (PCOA) showing the relationship between the bacterial population structures of the stone and plaster samples in the Maya archeological site, untreated and treated with the M-3P nutritional solution (based on Bray-Curtis index). Cl: Temple structure (Structure 18); CPN: stone block treated in the LACEM laboratory; and MC: lime plaster block treated in the LACEM laboratory.

Chloroflexi, Deinococcus-Thermus, and Planctomycetes were abundantly identified by $>1 \%$ of the total communities (Figure 3). Some other phyla such as Bacteroidetes, Gemmatimonadetes, Acidobacteria, Verrumicrobia, Nitrospirae, Candidate_division_OD1, Armatimonadetes, and Candidate_division_TM7 were detected in proportions below $1 \%$.

In the stone sample treated in situ (CI), many phyla including Cyanobacteria, Deinococcus-Thermus, Chloroflexi, Proteobacteria, Bacteroidetes, and Gemmatimonadetes reduced their proportions from 22.43, 11.68, 7.49, 3.90, 1.63, and $0.76 \%$ to $7.83,0.64,0.35,0.91,0.20$, and $0.01 \%$ after treatment with the M-3P nutritional solution, respectively, while Actinobacteria increased from $50.96 \%$ to $89.68 \%$ after the treatment (Figure 3). In the laboratory-treated stone sample (CPN), Actinobacteria and Firmicutes increased from 55.90 and $6.33 \%$ to 86.71 and $8.62 \%$, respectively, after treatment application. While others like Proteobacteria, Chloroflexi, Planctomycetes, Acidobacteria, Gemmatimonadetes, Verrumicrobia, Nitrospirae, and Bacteroidetes significantly reduced their proportions from 14.03, 9.95, 6.24, 1.46, 1.34, $1.24,0.83$, and $0.80 \%$ to $1.81,0.71,0.75,0.35,0.20,0.13,0.07$, and $0.22 \%$, respectively, after the bioconsolidation treatment. In the lime plaster sample (MC), Actinobacteria and Firmicutes increased their relative abundance after the treatment from 41.37 and $19.49 \%$ to 57.11 , and $41.81 \%$, respectively. In contrast, phyla such as Proteobacteria, Chloroflexi, Bacteroidetes, Planctomycetes, Acidobacteria, and Deinococcus-Thermus reduced their relative abundance from 20.91, 4.99, 3.81, 2.14, 1.92 , and $1.79 \%$ to $0.52,0.12,0.06,0.06,0.04$, and $0.00 \%$ after the treatment.
At genus level, identification of the bacterial groups revealed the presence of 485 different genera in the bacterial communities of all samples (Figure 4 and Supplementary Table 1). After the application of the in situ treatment (sample CI), genera such as Rubrobacter, Pseudonocardia, Microlunatus, Pseudomonas, Propioniferax, Microbacterium, Friedmanniella, and unclassifiedMicrococcaceae, among others, increased their proportion in comparison with untreated samples (i.e., samples collected before treatment), while others like Chroococcidiopsis, Mastigocladopsis, Truepera, Marmoricola, Nocardioides, Fibrisoma, and unclassified-Micromonosporaceae, decreased their proportions, by more than $50 \%$ in some cases, after the M-3P treatment. The untreated laboratory stone (CPN_CONT) was colonized by many bacteria including Crossiella, Nocardioides, Bacillus, Rhodococcus, Agrococcus, Pseudonocardia, Arthrobacter, Microlunatus, Microbacterium, Gemmata, Solirubrobacter, Iamia, unclassifiedNitrosomonadaceae, unclassified-Planctomycetaceae, Nitrospira, and Planctomyces. All these bacteria reduced their relative abundance after the treatment with the M-3P nutritional solution, with the exception of Streptomyces, unclassifiedMicrococcaceae, Fictibacillus, Agrococcus and Arthrobacter, which increased from 0.25 to $4.75 \%$, from 0.11 to $13.08 \%$, from 0.3 to $6.82 \%$, from 4.09 to $5.19 \%$, and from 2.36 to $51.73 \%$, respectively. A more diverse community was observed in the lime plaster sample (MC sample), where genera such as Nocardioides, Bacillus, Oxalophagus, Arthrobacter, Propionibacterium, Lachnospiraceae_Incertae_Sedis, unclassified-Rhizobiales, Sphingomonas, Microlunatus, Agrococcus, unclassifiedAcetobacteraceae, unclassified-Intrasporangiaceae, Marmoricola, unclassified-Paenibacillaceae, Deinococcus, Microvirga, Othaekwangia, Blastococcus, Gaiella, Adheribacter, 


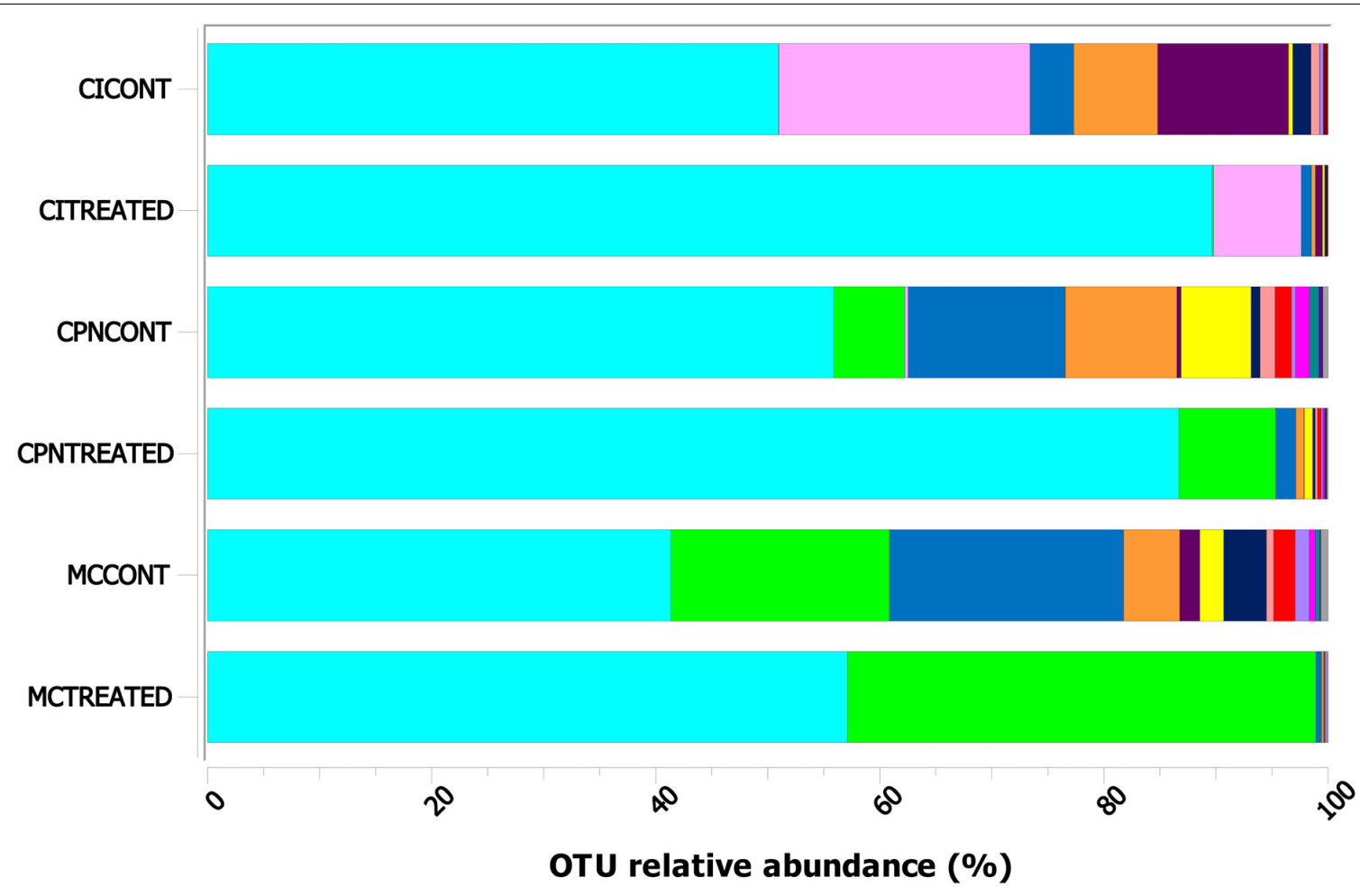

Actinobacteria
Deinococcus-Thermus
unclassified
Other

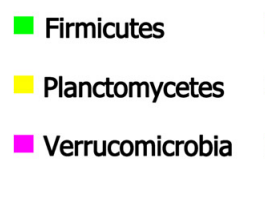

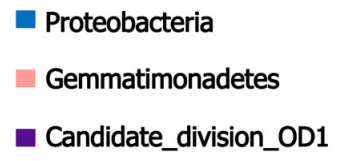

Chloroflexi

Acidobacteria

Armatimonadetes

FIGURE 3 | Taxonomic distribution of the bacterial community at phylum level in the stone and plaster samples of the Maya archeological site. Averages of relative abundance of three biological replicates from each sample are represented. Only phyla with a relative abundance of more than $0.1 \%$ are represented. Cl: stone block of the Temple structure; CPN: stone block treated at the LACEM laboratory; and MC: lime plaster block treated at the LACEM laboratory.

Solirubrobacter, Acinetobacter, and Granulicella dominated the bacterial community of the lime plaster before treatment. After the M-3P bioconsolidation treatment these bacteria significantly reduced their proportions. Other genera increased their relative abundance after the treatment such as Arthrobacter, Fictibacillus, Bacillus, and Agrococcus, which increased their relative abundance from $4.47,0.5,9.45$, and 2.85 to 32.83 , 20.86, 15.31, and 7.59\%, respectively. Microbacterium, Streptomyces, Paenibacillus, and unclassified members of Micromonosporaceae, Micrococcaceae, Microbacteriaceae, Bacillaceae, and Planococcaceae, also increased their relative abundance after the application of the treatment in MC sample and passed from less than $0.5 \%$ to $5.99,0.84,0.84,3.30,2.69$, $2.04,1.96$, and $1.29 \%$, respectively.

\section{Statistical Analyses and Correlation Network}

To further identify the similarity in abundance among the bacterial communities, a heatmap was produced based on the relative abundance of the genera with an average abundance of $>1.5 \%$ in at least one sample, which were defined as dominant. Abundance of 35 major genera present in all the samples was illustrated (Figure 5). Major genera with occupancies of $>80 \%$ of all samples were defined as common genera in the present study. Among these 35 major genera, 20 belonging mainly to Actinobacteria, 6 to Firmicutes, 4 to Proteobacteria, and 2 to DeinococcusThermus were considered as common genera. These included Rubrobacter, Arthrobacter, Crossiella, Fictibacillus, Nocardioides, Bacillus, Truepera, Micrococcaceae, Agrococcus, Oxalophagus, Microbacterium, Rhodococcus, Streptomyces, Propionibacterium, and Pseudonocardia.

Similarity of percentages analysis (SIMPER) was used to determine the relative contribution of each individual taxon to the dissimilarity among the three substrates (CI, CPN, and MC). The average Bray-Curtis dissimilarity and the contribution of each genus to the total dissimilarity between communities of treated and untreated samples were calculated, and the top major genera responsible for the microbial 


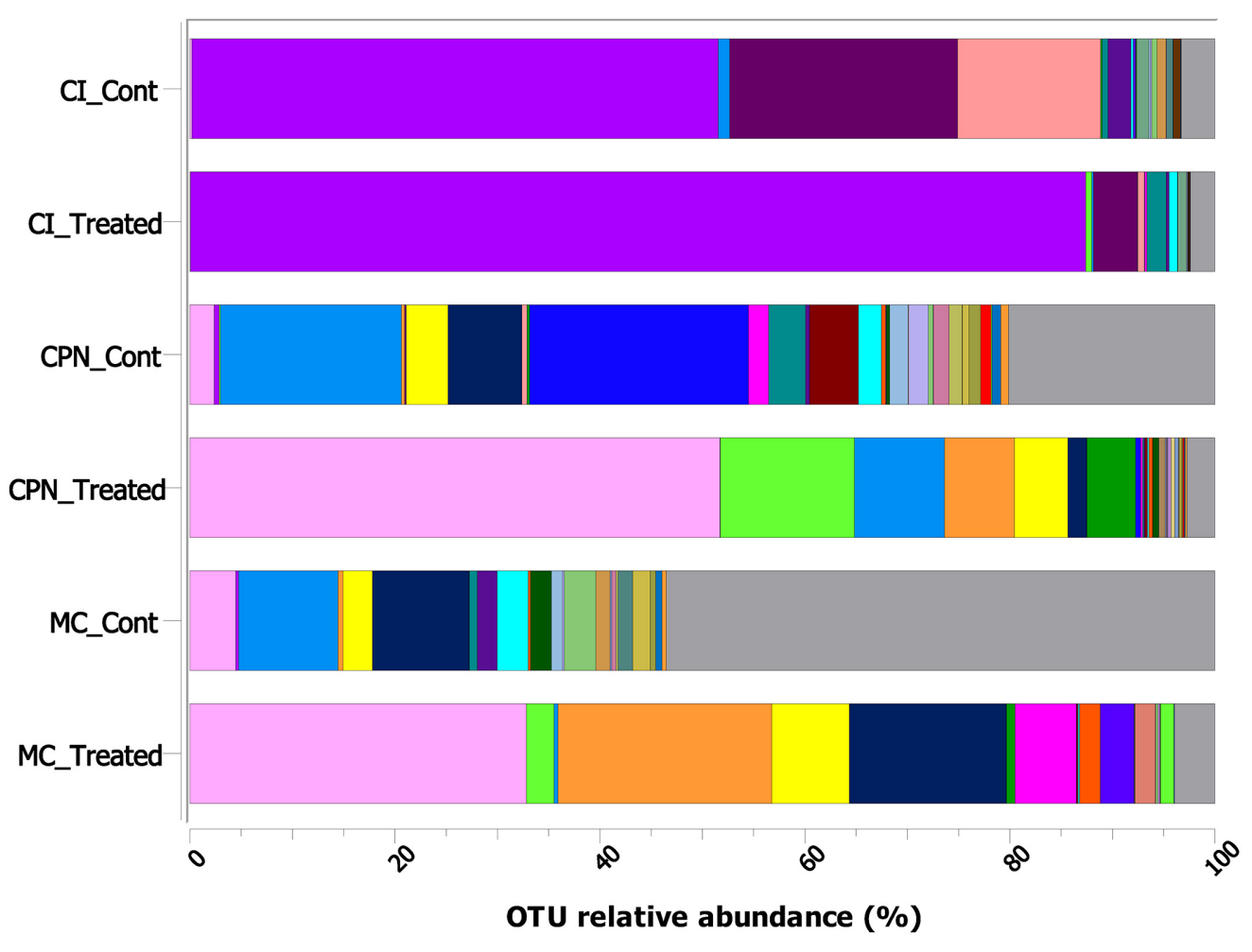

Arthrobacter
Nocardioides
Agrococcus
$\square$ Streptomyces
$\square$ Pseudonocardia
$\square$ Microlunatus
$\square$ Intrasporangiaceae_unclassified
Solirubrobacter
Sphingomonas
Promicromonospora
Nitrosomonadaceae_unclassified
Planctomycetaceae_Pir4_lineage
Planococcaceae_unclassified
Other

- Rubrobacter
- Fictibacillus
- Bacillus
- Crossiella
- Marmoricola
- Microbacteriaceae_unclassified
- Mastigocladopsis
- Bacillaceae_unclassified
- Saccharopolyspora
- O319-6M6_unclassified
- Gemmatimonadaceae_unclassified

- Micrococcaceae_unclassified

- Chroococcidiopsis

- Truepera

- Microbacterium

- Rhodococcus

- Micromonosporaceae_unclassified

- Brevibacterium

- Gemmata

Citricoccus

- Iamia

Ohtaekwangia

- Fibrisoma

Planctomycetaceae_unclassified

FIGURE 4 | Taxonomic distribution of the bacterial community at genus level in the stone and plaster samples of the Maya archeological site. Averages of relative abundance of three biological replicates from each sample are represented. Only genera with a relative abundance of more than $0.2 \%$ are represented. Cl: stone block of the Temple structure; CPN: stone block treated at the LACEM laboratory; and MC: lime plaster block treated at the LACEM laboratory.

community difference ( $>98 \%$ contribution to cumulative dissimilarity) are summarized in Tables 2, 3. Among the genera responsible for dissimilarity in the communities of untreated samples, Rubrobacter had the largest dissimilarity contribution (21.33\%), followed by Chroococcidiopsis (9.27\%), Crossiella (7.13\%), Nocardioides (6.24\%), Truepera (5.83\%), Bacillus (4.09\%), Oxalophagus (2.78\%), Arthrobacter (1.78\%), Agrococcus (1.66\%), Propionibacterium (1.62\%),
Rhodococcus (1.58\%), Microlunatus (1.53\%), Sphingomonas (1.15\%), and Pseudonocardia (1.10\%). After the bioconsolidation treatment, the genera contributing to the dissimilarity between the samples changed to some extent, being Rubrobacter again the largest dissimilarity contributor followed by Arthrobacter (21.16\%), Fictibacillus (8.53\%), Bacillus (6.26\%), unclassified_Micrococcaceae (5.11\%), Nocardioides (3.54\%), Agrococcus (3.10\%), Microbacterium 


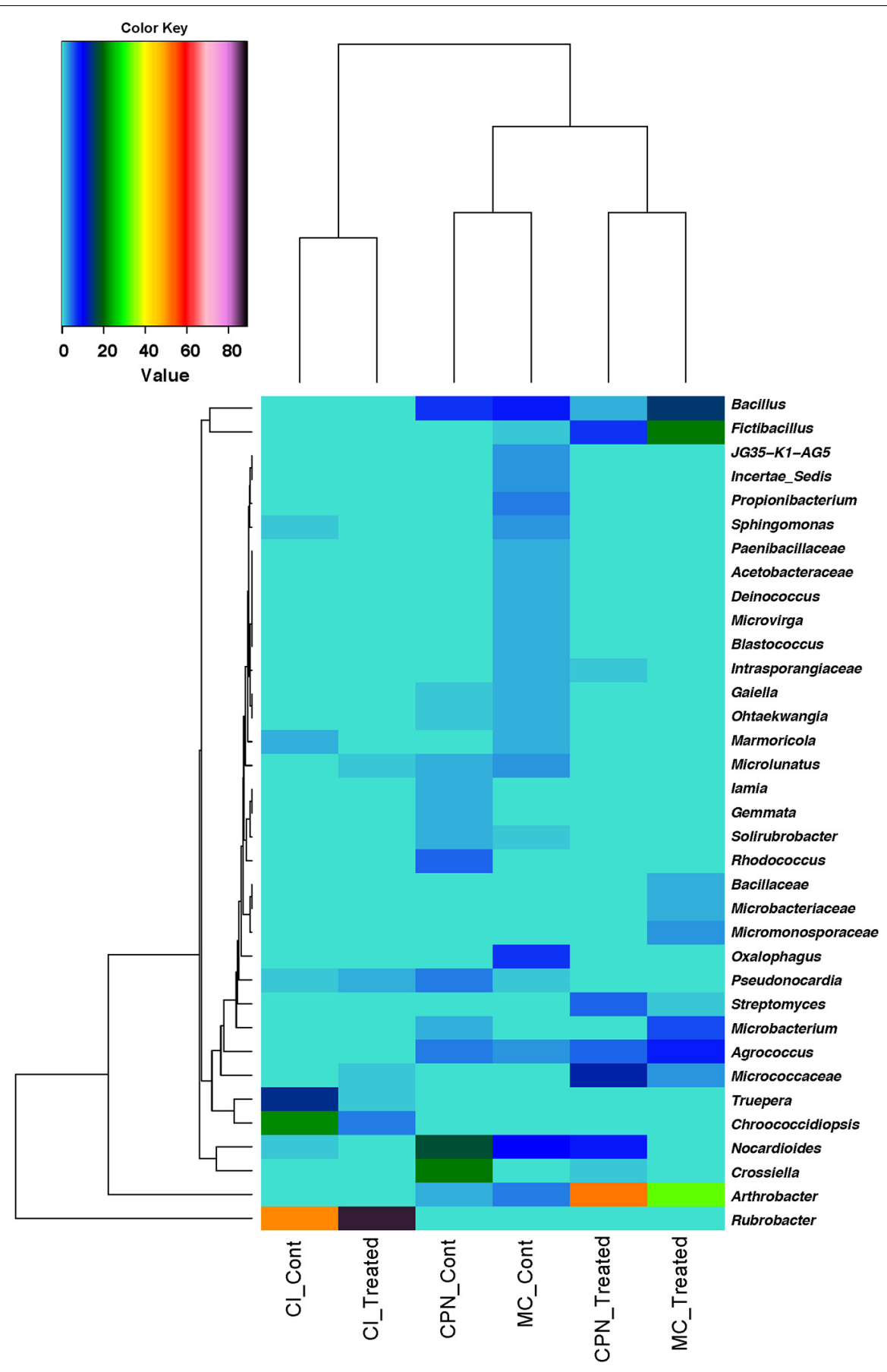

FIGURE $\mathbf{5}$ | Heatmap based on the relative abundance of genera with an average abundance of $>1.5 \%$ in at least one sample/replicate. Averages of relative abundance of three biological replicates from each sample are represented.

(2.39\%), Streptomyces (1.93\%), Chroococcidiopsis (1.76\%), and unclassified_Micromonosporaceae (1.35\%).

To comprehensively understand the interaction effects between bacteria detected before and after the application of the nutritional solution, a network of significant co-occurrence and co-exclusion relationships among genera was constructed on the basis of strong Pearson correlation matrix $(\rho>0.8$ or $\rho<-0.8$ ) (Figure 6). Among the 485 bacterial genera detected, those showing a relative abundance of more than $0.5 \%$ in at least one sample were used to construct this association network. A total of 73 nodes and 699 edges were identified. The network could be divided into three clear clusters formed by nodes interacting more strongly among themselves than with others. The three clusters were occupied by 4,14 , and 
TABLE 2 | SIMPER analysis of bacterial community dissimilarity ( $>98 \%$ of contribution to cumulative dissimilarity) of the three untreated Maya substrates (CI_CONT: stone sample in situ; CPN_CONT: stone sample in the LACEM laboratory; and MC_CONT: lime plaster in the LACEM laboratory).

\begin{tabular}{|c|c|c|c|c|c|c|}
\hline Taxon & $\begin{array}{l}\text { Avg dissimilarity } \\
(\%)\end{array}$ & $\begin{array}{l}\text { Contribution to } \\
\text { dissimilarity (\%) }\end{array}$ & $\begin{array}{c}\text { Cumulative } \\
\text { dissimilarity (\%) }\end{array}$ & \multicolumn{3}{|c|}{ Mean abundance (\%) } \\
\hline Rubrobacter & 18.24 & 21.33 & 21.33 & 51.3 & 0.494 & 0.282 \\
\hline Chroococcidiopsis & 7.931 & 9.276 & 30.61 & 22.2 & 0.153 & 0 \\
\hline Crossiella & 6.092 & 7.125 & 37.73 & 0.00152 & 21.3 & 0 \\
\hline Nocardioides & 5.333 & 6.236 & 43.97 & 1.1 & 17.6 & 9.63 \\
\hline Oxalophagus & 2.374 & 2.776 & 56.66 & 0 & 0.00134 & 6.65 \\
\hline Arthrobacter & 1.519 & 1.776 & 58.43 & 0.198 & 2.35 & 4.45 \\
\hline Agrococcus & 1.421 & 1.662 & 60.09 & 0.00656 & 4.09 & 2.84 \\
\hline Propionibacterium & 1.381 & 1.615 & 61.71 & 0.00694 & 0.0196 & 3.87 \\
\hline Rhodococcus & 1.354 & 1.583 & 63.29 & 0.000829 & 4.74 & 0 \\
\hline Pseudonocardia & 0.9415 & 1.101 & 69.78 & 0.54 & 3.58 & 0.761 \\
\hline Unclassified_Acetobacteraceae & 0.8125 & 0.9502 & 70.73 & 0.0348 & 0.0135 & 2.27 \\
\hline Unclassified_Intrasporangiaceae & 0.6897 & 0.8066 & 71.53 & 0.118 & 0.312 & 2.05 \\
\hline Deinococcus & 0.6463 & 0.7558 & 72.29 & 0.101 & 0 & 1.75 \\
\hline Unclassified_Paenibacillaceae & 0.6423 & 0.7512 & 73.04 & 0 & 0.00293 & 1.8 \\
\hline Ohtaekwangia & 0.6238 & 0.7295 & 73.77 & 0 & 0.619 & 1.68 \\
\hline Microvirga & 0.6036 & 0.7059 & 74.48 & 0.00809 & 0.0369 & 1.7 \\
\hline Marmoricola & 0.6028 & 0.705 & 75.18 & 2.24 & 0.415 & 1.93 \\
\hline Gaiella & 0.5787 & 0.6768 & 75.86 & 0 & 0.809 & 1.62 \\
\hline Blastococcus & 0.5766 & 0.6744 & 76.53 & 0.0258 & 0.0181 & 1.63 \\
\hline
\end{tabular}

TABLE 3 | SIMPER analysis of bacterial community dissimilarity (>98\% of contribution to cumulative dissimilarity) of the three treated Maya substrates (CI_TREAT: stone sample treated in situ; CPN_TREAT: stone sample treated in the LACEM laboratory; and MC_TREAT: lime plaster treated in the LACEM laboratory).

\begin{tabular}{|c|c|c|c|c|c|c|}
\hline Taxon & $\begin{array}{l}\text { Avg dissimilarity } \\
(\%)\end{array}$ & $\begin{array}{l}\text { Contribution to } \\
\text { dissimilarity (\%) }\end{array}$ & $\begin{array}{c}\text { Cumulative } \\
\text { dissimilarity (\%) }\end{array}$ & \multicolumn{3}{|c|}{ Mean abundance (\%) } \\
\hline Rubrobacter & 29.09 & 35.74 & 35.74 & 87.30 & 0.02 & 0.01 \\
\hline Arthrobacter & 17.22 & 21.16 & 56.90 & 0.06 & 51.70 & 32.80 \\
\hline Fictibacillus & 6.94 & 8.53 & 65.43 & 0.01 & 6.82 & 20.80 \\
\hline Bacillus & 5.09 & 6.26 & 71.69 & 0.01 & 1.84 & 15.30 \\
\hline Agrococcus & 2.52 & 3.10 & 83.44 & 0.01 & 5.19 & 7.58 \\
\hline Microbacterium & 1.94 & 2.39 & 85.83 & 0.22 & 0.20 & 5.98 \\
\hline Streptomyces & 1.57 & 1.93 & 87.76 & 0.02 & 4.73 & 0.84 \\
\hline Chroococcidiopsis & 1.43 & 1.76 & 89.52 & 4.30 & 0.00 & 0.00 \\
\hline Unclassified_Micromonosporaceae & 1.10 & 1.35 & 90.87 & 0.02 & 0.02 & 3.30 \\
\hline
\end{tabular}




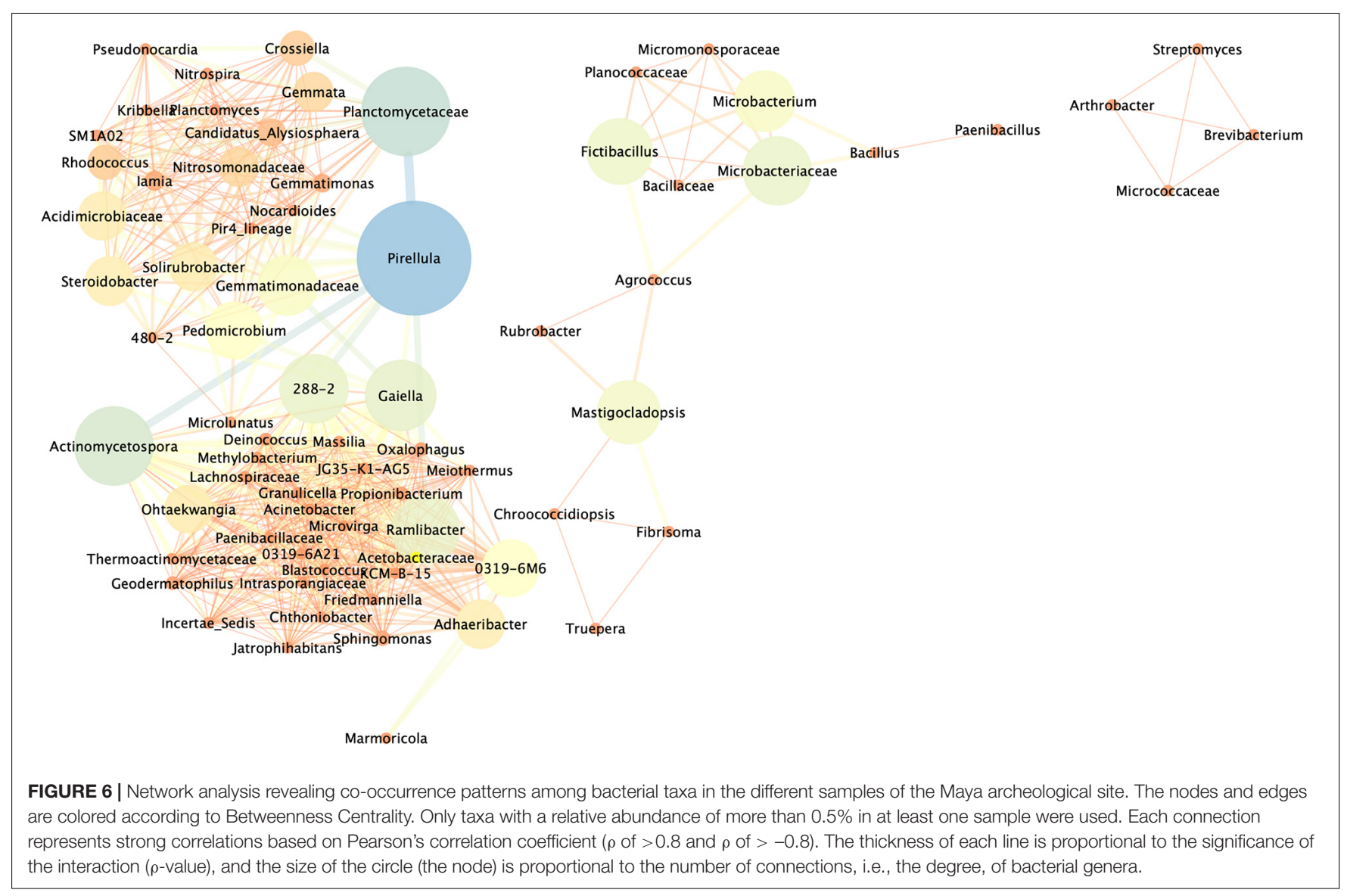

55 nodes out of the 73 total vertices and, with the exception of three (i.e., Rubrobacter, Agrococcus, and Mastigocladopsis) all were found to be strongly positively correlated. In the first cluster, Arthrobacter, Streptomyces, Micrococcaceae, and Brevibacterium were equally distributed and no keystones were distinguished over the rest of the bacteria, being nodes with low mean degree and low Betweenness Centrality. Microbacterium, Fictibacillus, Microbacteriaceae, and Mastigocladopsis were considered potential keystones in the second cluster showing strong correlation connections with the rest of core bacteria in the cluster. In the most complex cluster, the 55 nodes formed a complex network with strong interactions and taxa like Planctomycetaceae, Pirellula, Gaiella, Solirubrobacter, Gemmatimonadaceae, Pedomicrobium, Acidimicrobiaceae, Ramlibacter, among others, which were considered keystone bacteria, exhibiting strong positive correlations with other core genera. Finally, only three genera Rubrobacter, Agrococcus and Mastigocladopsis presented negative Pearson correlation matrix $(\rho<-0.8)$ in the community, meaning that the presence of Rubrobacter was negatively correlated with the presence of Agrococcus and Mastigocladopsis in the bacterial population. The presence of Matigocladopsis was also negatively correlated with the presence of Agrococcus. For this reason, Rubrobacter was only present in the temple Structure 18, whereas Agrococcus was only detected in the stone sample CPN and the mortar sample MC treated indoors in the laboratory.

\section{DISCUSSION}

\section{Before Treatment}

High-throughput sequencing results in our study revealed a rich diversity of bacterial communities on the deteriorated stone and plaster samples of the Maya archeological site. We identified a total of 161 genera in the CI_Cont, 309 in CPN_Cont, and 141 in MC_Cont. Association networks constructed to the genus level showed mainly positive correlation patterns with strong and complex connections, as well as some negative correlations with loose and simple connections. These interactions between microbial taxa in stone and plaster artworks indicated significant co-occurrence patterns helping to decipher the relationships between community members. Most of these genera belong to Actinobacteria, Cyanobacteria, and Firmicutes, which are identified as the keystone taxa and contribute to the association of the bacterial community, suggesting either shared or preferred environmental conditions or the performance of similar or complementary functions (Jroundi et al., 2020).

Generally, microbial communities in archeological sites have been reported to have distinct diversity patterns under different environmental conditions (Gaylarde et al., 2007; Piñar et al., 2015; Li et al., 2016; Dhami et al., 2017; Mihajlovski et al., 2017; Sterflinger et al., 2018). The results of this study show that the microbial community patterns detected 
on archeological/historic stone and mortar surfaces not only depended on the overall environmental conditions, but were also greatly influenced by the location of each individual building or decorative element within the archeological Maya site. Data presented (in Figure 4 and Table 2) reveal that the microbial population of the untreated stone sample (CI) from a vertical wall of Structure 18 was dominated by Rubrobacter, Chroococcidiopsis, and Truepera. Remarkably, these bacteria were completely absent from the remaining untreated stone and plaster floor samples (CPN and MC), which were in direct contact with the ground. Consequently, these genera, and particularly Rubrobacter, had the largest contribution to bacterial community dissimilarity. Members of Rubrobacter sp. have been isolated from a range of environmental samples including different soil niches (Holmes et al., 2000) and many monuments including the Mayan ruins of Uxmal (Mexico) (Ortega-Morales et al., 2004; Sterflinger and Piñar, 2013; Mihajlovski et al., 2017; Adamiak et al., 2018). They are known to be thermophilic, halotolerant, and gamma-radiation resistant bacteria, which also colonize salt laden building materials (Laiz et al., 2009; Jurado et al., 2012; Adamiak et al., 2018). The preferential colonization of Rubrobacter on the vertical walls of Structure 18 confirms previous results, indicating that their resistance toward temporary desiccation and intensive daylight irradiation would bestow them a selective advantage over other bacteria (Laiz et al., 2009). Often, the presence of Rubrobacter has been associated with biodeterioration processes/phenomena in monuments, including pink discoloration (Ortega-Morales et al., 2004; Laiz et al., 2009; Sterflinger and Piñar, 2013; Mihajlovski et al., 2017; Adamiak et al., 2018). Laiz et al. (2009) associated stone biodeterioration with the Rubrobacter-induced precipitation of struvite $\left(\mathrm{NH}_{4} \mathrm{MgPO}_{4} \cdot 6 \mathrm{H}_{2} \mathrm{O}\right)$, a mineral which is also produced by other carbonatogenic bacteria such as Myxococcus xanthus cultured in $\mathrm{Mg}$ - and phosphate-containing medium (González-Muñoz et al., 2008). Note that the latter bacterium has an outstanding biomineralization capacity and is known to produce cementing calcium carbonate under adequate conditions (Rodriguez-Navarro et al., 2003). Furthermore, the possible role of struvite precipitation by Rubrobacter inducing salt damage in stone as suggested by Laiz et al. (2009) is questionable, considering its low solubility. Struvite is a sparingly soluble phase with solubility of $4.07 \times 10^{-5} \mathrm{~mol} / \mathrm{L}$ at $25^{\circ} \mathrm{C}$ (Hanhoun et al., 2011), a value slightly lower than that of calcite $\left(5.75 \times 10^{-5} \mathrm{~mol} / \mathrm{L}\right)$, a benign sparingly soluble carbonate. In fact, calcite effectively cements porous stone, being the basis of the bacterial biomineralization consolidation treatment (Rodriguez-Navarro et al., 2015). It seems even possible that struvite could act as a consolidant as it has been reported in the case of other alkaline-earth phosphates such as hydroxyapatite (Sassoni et al., 2011).

In general, the microbial communities living in the archeological sites or historical buildings all over the world are linked to environmental conditions (Gaylarde et al., 2007; Li et al., 2016). The high-throughput sequencing results in our study revealed a rich diversity of bacterial communities on the stone and plaster samples of the Maya archeological site. Indeed, although samples showed similar signs of biodeterioration and microbial colonization, overall, the microbial diversity in this study varied enormously in composition, seemingly affected by sample location, substrate type (i.e., silicate tuff stone $v s$. calcium carbonate lime plaster), and environmental conditions.

The diversity of the bacterial communities in samples CPN (stone) and MC (mortar) was almost twice as large as compared with sample CI (stone in Structure 18). Possibly, the direct contact with the soil microbiota of the ground had a significant impact on the bacterial population in the former samples. Remarkably, the degree of similarity was higher between the stone sample CPN and mortar sample MC than between the two volcanic tuff stone samples, indicating that the original sample location was of greater importance than substrate characteristics (composition, mineralogy and textural features). Additionally, Bacillus was detected in all samples, which was not surprising since many members of these bacteria have been identified on stone surfaces and are frequently used for the bioconsolidation of deteriorated historical monuments and sculptures of different substrate types including calcareous stone, concrete and mortars (Dhami et al., 2012, 2014; Achal et al., 2013; Wang et al., 2014; Montaño-Salazar et al., 2018). Other genera such as Agrococcus, Pseudonocardia, Microlunatus, Pseudomonas, Propioniferax, Microbacterium, and Friedmanniella (the latter 4 were present at concentrations below $0.1 \%$ and are not included in Figure 4) were also detected in our study, which have the ability to survive in extreme environments and were previously identified in archeological sites (Li et al., 2016), caves (Portillo et al., 2009; Fang et al., 2017), Roman catacombs (Krakova et al., 2015), wall paintings of a medieval chapel in Austria (Schabereiter-Gurtner et al., 2001), and on the tomb walls of an Etruscan Necropolis (Diaz-Herraiz et al., 2013). Although present at low relative abundance, some bacteria are able to play an important role in many environments because of their high metabolic activity. Some of them such as Pseudomonas strains have been shown to precipitate calcium carbonate crystals in the surface of bacterial isolates and are considered among the most common microorganisms detected on stone monuments (Li et al., 2018). Pseudonocardia sp. have been previously detected as a dominant component of the microbial community in caves, wall paintings, tomb walls and Roman catacombs (Portillo et al., 2009; Diaz-Herraiz et al., 2013; Krakova et al., 2015). Some studies demonstrated that members of this genus, and of the phylum Actinobacteria in general, were able to precipitate calcium carbonate in culture media supplemented by different calcium salts (Fang et al., 2017), suggesting their potential to precipitate such calcium carbonate to consolidate stone of cultural heritage; although this needs to be confirmed by further studies.

Finally, members of the phylum Acidobacteria were detected in CPN and MC samples. Many studies have reported the presence of these non-culturable Acidobacteria in cave habitats, including catacombs (Zimmermann et al., 2006). Acidobacteria seem to adapt well to low nutrient substrates, which corroborates their possible oligotrophic lifestyle in many environmental habitats (Naether et al., 2012). They are also known to be acidophilic, strictly aerobic, chemo-organotrophic 
bacteria, capable of degrading sugars and some polysaccharides (Pankratov et al., 2012).

\section{After Treatment}

Regardless of treatment location (i.e., in situ or ex situ) the application of the patented nutritional solution (M-3P) caused an important change in bacterial population in all samples, particularly increasing the amount of Actinobacteria in samples CI, CPN, and MC by $89.68,86.71$, and $57.11 \%$, respectively. The increase in the amount of carbonatogenic Actinobacteria can be considered as an indicator for the potential efficacy of this bioconsolidation treatment since this bacterial phylum is known to be able to utilize various carbon and nitrogen sources and produce calcium carbonate (Fang et al., 2017). Remarkably, the increase in Actinobacteria was more pronounced in stone samples as compared to the mortar sample, where Firmicutes (dominated by the genera Fictibacillus and Bacillus) became the second most dominant phylum (increasing from 19.49 to $41.81 \%)$. These bacteria are found in various environments and can survive extreme conditions. Some of them are known for their endospores production, which makes them resistant to desiccation (Parkes and Sass, 2009; Nazir et al., 2019). These bacteria, specially Bacillus spp., have been suggested to have a direct relationship with carbonate deposition and have been widely used for the consolidation and strengthening of sand columns and soils, the repairment of concrete cracks and in the field of limestone building conservation, showing in all cases a high capacity to precipitate calcite and vaterite (Le MétayerLevrel et al., 1999; De Muynck et al., 2010, 2013; García et al., 2016).

Our results show that the composition of the original bacterial population has an important influence on the bacterial population developed after the consolidation treatment. In the case of the stone sample from Structure 18 (CI), Rubrobacter remained the dominant genus, experiencing an increase in relative abundance of $66 \%$ after the bioconsolidation treatment, whereas all other genera suffered an, in certain cases dramatic (i.e., Truepera and Chroococcidiopsis), decrease. It is very likely that Rubrobacter would play a relevant role in the production of calcium carbonate cement, without any detrimental side effects (e.g., salt damage or discoloration). As stated above, it is very unlikely that Rubrobacter-induced struvite precipitation could have any salt damaging effect. Besides, struvite formation after application of the M-3P treatment is improbable, as this medium lacks magnesium. In contrast, it is very likely that Rubrobacter can effectively contribute to the biomineralization of calcium carbonates. On the one hand, it has been shown that Rubrobacter spp. are associated with $\mathrm{CaCO}_{3}$ precipitation in endostromatolites (Pellerin et al., 2009). On the other hand, the observed increase in Rubrobacter abundance after the M$3 \mathrm{P}$ treatment is consistent with this bacterium being able to use amino acids for its metabolic activity. It is thus expected that it contributes to an alkalinization of the medium resulting in the formation of cementing calcium carbonates. Regarding any potential problems of discoloration associated with this bacterium, as it is indicated in the Materials and Methods section, we covered the substrates during the whole duration of the treatment to prevent light irradiation of treated surfaces, precisely to avoid any possible pigmentation by bacteria. Actually, we observed no color changes/discoloration 3 months after treatment application. In any case, a detailed characterization of the untreated and treated substrate (i.e., compositional, textural and physico-mechanical analysis) is currently underway in order to proof bacterial carbonate biomineralization and to rule out possible negative side effects.

In samples $\mathrm{CPN}$ and $\mathrm{MC}$, Arthrobacter showed the strongest response to the nutritional supply and became the dominant genus, augmenting its relative abundance by a factor of $21.9 \mathrm{x}$ and $7.3 \mathrm{x}$, respectively. Consequently, they have, after Rubrobacter, the second largest contribution to bacterial community dissimilarity in treated samples. Jroundi et al. (2012) have shown that Arthrobacter species are promising candidates for successful biomineralization induced by the application of a nutritional solution that selectively activates carbonatogenic bacteria. The observed improved mechanical strength in treated monumental stone and mortars, especially in the case of Arthrobacter crystallopoietes, has even prompted their consideration for industrial applications (Park et al., 2010; Dhami et al., 2012, 2014; Jroundi et al., 2012; Montaño-Salazar et al., 2018). Other carbonatogenic bacteria, including Fictibacillus, Bacillus, Streptomyces, and Agrococcus also reacted positively to the treatment and increased their abundance.

Remarkably, members of the phylum Acidobacteria were also significantly affected by the bioconsolidation treatment, experiencing an important decrease of 76 and $98 \%$ in abundance in the case of sample CPN and MC, respectively. Zimmermann et al. (2006) reported on their active negative role on cultural heritage in collaboration with other microorganisms. The acidic metabolic products of these bacteria have been shown to cause severe irreversible damage to stone monuments, leading to the dissolution of the stone matrix, especially in the case of calcareous rocks (Douglas and Beveridge, 1998; Warscheid and Braams, 2000). Therefore, such a negative impact of this bioconsolidation treatment on Acidobacteria can be taken as additional evidence for the suitability of the proposed strategy for the consolidation and conservation of monuments and archeological sites in tropical hot and humid environments.

\section{CONCLUSION}

In this study, we showed for the first time the enormous impact of the bioconsolidation methodology based on the application of a sterile nutritive solution (M-3P) on the indigenous bacteria present in stone and plaster at the Maya archeological site of Copan. A detailed characterization of the bacterial population evolution revealed that the bioconsolidation treatment induced a significant increase in beneficial indigenous carbonatogenic bacteria and a concomitant suppression of potentially damaging Acidobacteria. Positive results were obtained under varying treatment conditions (i.e., treatments in the laboratory and in situ) and independent of substrate type (i.e., stone and mortar). This study also revealed that the original bacterial population of the substrate was decisive for the population 
evolution upon treatment, being influenced by the location of the sample within the archeological site (i.e., stone samples from vertical walls versus semi-buried stone and floor plaster fragments with contact to soil microbiota). Importantly, the application of the sterile M-3P nutritive solution did not result in the flourishing of any damaging bacteria in this hot and humid environment. At present we are evaluating the consolidation effect of such a treatment applied on Maya stones and plasters of Copan, focusing on the quantification and distribution of the newly formed bacterial calcium carbonate cement and its impact on the treated substrates' physical-mechanical properties. Combined results will lay the basis for the development of an environmentally friendly compatible conservation treatment for monuments in hot and humid climates based on the bacterial precipitation of cementing calcium carbonate for the consolidation of plaster and stone.

Furthermore, the relative safety and ease of application of the treatment proposed here as compared to conventional biotreatments using bacteria inoculums are worth highlighting. The former simply consists of spraying the patented nutritional solution onto the degraded substrate surface, allowing for largescale applications without posing any significant risk to operator or environment. Admittedly, the biotreatment is labor intensive (i.e., relatively large number of applications are required). However, overall material-related treatment costs are comparable to those of conventional consolidation treatments.

\section{DATA AVAILABILITY STATEMENT}

All raw sequences used in this study are available in the sequence read archive (SRA) at NCBI database under the SRA accession number PRJNA650538.

\section{AUTHOR CONTRIBUTIONS}

CR-N and MTG-M conceived the concept and led this project. CR-N and FJ designed the experimental setup. CR-N, KE,

\section{REFERENCES}

Achal, V., Mukerjee, A., and Sudhakara Reddy, M. (2013). Biogenic treatment improves the durability and remediates the cracks of concrete structures. Constr. Build. Mater. 48, 1-5. doi: 10.1016/j.conbuildmat.2013.06. 061

Adamiak, J., Otlewska, A., Tafer, H., Lopandic, K., Gutarowska, B., Sterflinger, K., et al. (2018). First evaluation of the microbiome of built cultural heritage by using the Ion Torrent next generation sequencing platform. Int. Biodeterior. Biodegrad. 131, 11-18. doi: 10.1016/j.ibiod.2017.01. 040

Boquet, E., Boronat, A., and Ramos-Cormenzana, A. (1973). Production of calcite (Calcium Carbonate) crystals by soil bacteria is a general phenomenon. Nature 246, 527-529. doi: 10.1038/246527a0

Caneva, G., Salvadori, O., Ricci, S., and Ceschin, S. (2005). Ecological analysis and biodeterioration processes over time at the hieroglyphic stairway in the Copán (Honduras) archaeological site. Plant Biosyst. Int. J. Deal. Aspects Plant Biol. 139, 295-310. doi: 10.1080/11263500500343353

Caporaso, J. G., Kuczynski, J., Stombaugh, J., Bittinger, K., Bushman, F. D., Costello, E. K., et al. (2010). QIIME allows analysis of high-throughput and ER-A set up and managed the treatment and the sample collections. FJ performed all laboratory works, analyzed the data, and created the graphs and figures. FJ, KE, and CR-N were major contributors in writing the manuscript with critical input from MTG-M, and ER-A. All authors read and approved the final version of the manuscript.

\section{FUNDING}

The authors would like to acknowledge funding by the Santander Program, Peabody Museum (Harvard University) and the David Rockefeller Center for Latin American Studies (DRCLAS) at Harvard University under the "Research and Conservation of Maya Sculpture" project. Additional funding was provided by the Spanish Government (grant RTI2018-099565-B-I00), the Junta de Andalucía (research groups RNM-179 and BIO 103), and the University of Granada (Unidad Científica de Excelencia UCEPP2016-05).

\section{ACKNOWLEDGMENTS}

We thank William Fash and Barbara Fash as well as the team at the Maya Sculpture Conservation Laboratory (LACEM) in Copan for their help and continuous support, as well as for providing access to this Maya archeological site and their contribution to the sampling and treatment application process. We also thank Alberto de Tagle and Nieves Valentin for their help and support during the development of this study.

\section{SUPPLEMENTARY MATERIAL}

The Supplementary Material for this article can be found online at: https://www.frontiersin.org/articles/10.3389/fmicb. 2020.599144/full\#supplementary-material

community sequencing data. Nat. Methods 7, 335-336. doi: 10.1038/nmeth.f. 303

Delgado-Rodrigues, J., and Ferreira-Pinto, A. P. (2019). Stone consolidation by biomineralisation. Contribution for a new conceptual and practical approach to consolidate soft decayed limestones. J. Cult. Herit. 39, 82-92. doi: 10.1016/j. culher.2019.04.022

De Muynck, W., De Belie, N., and Verstraete, W. (2010). Microbial carbonate precipitation in construction materials: a review. Ecol. Eng. 36, 118-136. doi: 10.1016/j.ecoleng.2009.02.006

De Muynck, W., Verbeken, K., De Belie, N., and Verstraete, W. (2013). Influence of temperature on the effectiveness of a biogenic carbonate surface treatment for limestone conservation. Appl. Microbiol. Biotechnol. 97, 1335-1347. doi: 10.1007/s00253-012-3997-0

Dhami, N. K., Alsubhi, W. R., Watkin, E., and Mukherjee, A. (2017). Bacterial community dynamics and biocement formation during stimulation and augmentation: implications for soil consolidation. Front. Microbiol. 8:1267. doi: 10.3389/fmicb.2017.01267

Dhami, N. K., Reddy, M. S., and Mukherjee, A. (2012). Improvement in strength properties of ash bricks by bacterial calcite. Ecol. Eng. 39, 31-35. doi: 10.1016/j. ecoleng.2011.11.011 
Dhami, N. K., Reddy, M. S., and Mukherjee, A. (2014). Application of calcifying bacteria for remediation of stones and cultural heritages. Front. Microbiol. 5:304. doi: 10.3389/fmicb.2014.00304

Diaz-Herraiz, M., Jurado, V., Cuezva, S., Laiz, L., Pallecchi, P., Tiano, P., et al. (2013). The actinobacterial colonization of etruscan paintings. Sci. Rep. 3:1440. doi: 10.1038/srep01440

Doehne, E., Simon, S., Mueller, U., Carson, D., and Ormsbee, A. (2005). Characterization of carved rhyolite tuff-the hieroglyphic stairway of Copan, Honduras. Restor. Build. Monum. 11, 247-254. doi: 10.1515/rbm-2005-5973

Douglas, S., and Beveridge, T. J. (1998). Mineral formation by bacteria in natural microbial communities. FEMS Microbiol. Ecol. 26, 79-88. doi: 10.1111/j.15746941.1998.tb00494.x

Ettenauer, J., Piñar, G., Sterflinger, K., Gonzalez-Muñoz, M. T., and Jroundi, F. (2011). Molecular monitoring of the microbial dynamics occurring on historical limestone buildings during and after the in situ application of different bioconsolidation treatments. Sci. Total Environ. 409, 5337-5352. doi: 10.1016/j. scitotenv.2011.08.063

Fang, B. Z., Salam, N., Han, M. X., Jiao, J. Y., Cheng, J., Wei, D. Q., et al. (2017). Insights on the effects of heat pretreatment, $\mathrm{pH}$, and calcium salts on isolation of rare actinobacteria from karstic caves. Front. Microbiol. 8:1535. doi: $10.3389 /$ fmicb.2017.01535

Fash, W. L. Jr., Williamson, R. V., Larios, R., and Palka, J. (1992). The hieroglyphic stairway and its ancestors. Ancient Mesoam. 3, 105-115. doi: 10.1017/ s0956536100002339

Fash, W. L. (1991). Scribes, Warriors, and Kings. New York, NY: Thames and Hudson.

García, G. M., Márquez, G. M. A., and Moreno, H. C. X. (2016). Characterization of bacterial diversity associated with calcareous deposits and drip-waters, and isolation of calcifying bacteria from two Colombian mines. Microbiol. Res. 182, 21-30. doi: 10.1016/j.micres.2015.09.006

Gaylarde, C. C., Ortega-Morales, B. O., and Bartolo-Pérez, P. (2007). Biogenic black crusts on buildings in unpolluted environments. Curr. Microbiol. 54, 162-166. doi: 10.1007/s00284-006-0432-8

Gil, E., Mas, Á, Lerma, C., and Vercher, J. (2015). Exposure factors influence stone deterioration by crystallization of soluble salts. Adv. Mater. Sci. Eng. 2015:348195. doi: 10.1155/2015/348195

Giorgi, R., Baglioni, M., Berti, D., and Baglioni, P. (2010). New methodologies for the conservation of cultural heritage: micellar solutions, microemulsions, and hydroxide nanoparticles. Acc. Chem. Res. 43, 695-704. doi: 10.1021/ar900193h

González-Muñoz, M. T., Rodriguez-Navarro, C., Jimenez-Lopez, C., and Rodriguez-Gallego, M. (2008). Method and product for protecting and reinforcing construction and ornamental materials. Spanish patent P200602030 (WO2008009771)

Hanhoun, M., Montastruc, L., Azzaro-Pantel, C., Biscans, B., Frèche, M., and Pibouleau, L. (2011). Temperature impact assessment on struvite solubility product: a thermodynamic modeling approach. Chem. Eng. J. 167, 50-58. doi: 10.1016/j.cej.2010.12.001

Holmes, A. J., Bowyer, J., Holley, M. P., O’Donoghue, M., Montgomery, M., and Gillings, M. R. (2000). Diverse, yet-to-be-cultured members of the Rubrobacter subdivision of the Actinobacteria are widespread in Australian arid soils. FEMS Microbiol. Ecol. 33, 111-120. doi: 10.1111/j.1574-6941.2000.tb 00733.x

Jiang, W., Liang, P., Wang, B., Fang, J., Lang, J., Tian, G., et al. (2015). Optimized DNA extraction and metagenomic sequencing of airborne microbial communities. Nat. Protoc. 10, 768-779. doi: 10.1038/nprot.2015.046

Jroundi, F., Descostes, M., Povedano-Priego, C., Sánchez-Castro, I., Suvannagan, V., Grizard, P., et al. (2020). Profiling native aquifer bacteria in a uranium roll-front deposit and their role in biogeochemical cycle dynamics: insights regarding in situ recovery mining. Sci. Total Environ. 721:137758. doi: 10.1016/ j.scitotenv.2020.137758

Jroundi, F., Gómez-Suaga, P., Jimenez-Lopez, C., González-Muñoz, M. T., and Fernandez-Vivas, M. A. (2012). Stone-isolated carbonatogenic bacteria as inoculants in bioconsolidation treatments for historical limestone. Sci. Total Environ. 425, 89-98. doi: 10.1016/j.scitotenv.2012.02.059

Jroundi, F., Schiro, M., Ruiz-Agudo, E., Elert, K., Martín-Sánchez, I., GonzálezMuñoz, M. T., et al. (2017). Protection and consolidation of stone heritage by self-inoculation with indigenous carbonatogenic bacterial communities. Nat. Commun. 8:279. doi: 10.1038/s41467-017-00372-3
Jurado, V., Miller, A. Z., Alias-Villegas, C., Laiz, L., and Saiz-Jimenez, C. (2012). Rubrobacter bracarensis sp. nov., a novel member of the genus Rubrobacter isolated from a biodeteriorated monument. Syst. Appl. Microbiol. 35, 306-309. doi: 10.1016/j.syapm.2012.04.007

Klindworth, A., Pruesse, E., Schweer, T., Peplies, J., Quast, C., Horn, M., et al. (2013). Evaluation of general 16 S ribosomal RNA gene PCR primers for classical and next-generation sequencing-based diversity studies. Nucleic Acids Res. 41:e1. doi: 10.1093/nar/gks808

Krakova, L., De Leo, F., Bruno, L., Pangallo, D., and Urzì, C. (2015). Complex bacterial diversity in the white biofilms of the Catacombs of St. Callixtus in Rome evidenced by different investigation strategies. Environ. Microbiol. 17, 1738-1752. doi: 10.1111/1462-2920.12626

Laiz, L., Miller, A. Z., Jurado, V., Akatova, E., Sanchez-Moral, S., Gonzalez, J. M., et al. (2009). Isolation of five Rubrobacter strains from biodeteriorated monuments. Naturwissenschaften 96, 71-79. doi: 10.1007/s00114-008-0452-2

Le Métayer-Levrel, G., Castanier, S., Orial, G., Loubière, J. F., and Perthuisot, J. P. (1999). Applications of bacterial carbonatogenesis to the protection and regeneration of limestones in buildings and historic patrimony. Sediment. Geol. 126, 25-34. doi: 10.1016/S0037-0738(99)00029-9

Li, Q., Zhang, B., He, Z., and Yang, X. (2016). Distribution and diversity of bacteria and fungi colonization in stone monuments analyzed by high-throughput sequencing. PLoS One 11:e0163287. doi: 10.1371/journal.pone.0163287

Li, Q., Zhang, B., Yang, X., and Ge, Q. (2018). Deterioration-associated microbiome of stone monuments: structure, variation, and assembly. Appl. Environ. Microbiol. 84:e02680-17. doi: 10.1128/AEM.02680-17

Marvasi, M., Cavalieri, D., Mastromei, G., Casaccia, A., and Perito, B. (2019). Omics technologies for an in-depth investigation of biodeterioration of cultural heritage. Int. Biodeterior. Biodegrad. 144:104736. doi: 10.1016/j.ibiod.2019. 104736

Masella, A. P., Bartram, A. K., Truszkowski, J. M., Brown, D. G., and Neufeld, J. D. (2012). PANDAseq: paired-end assembler for illumina sequences. BMC Bioinform. 13:31. doi: 10.1186/1471-2105-13-31

McVey, L. (1998). A Characterization and Analysis of the Floor Plasters from the Acropolis at Copan, Honduras. MS Thesis. Philadelphia, PA: University of Pennsylvania.

Mihajlovski, A., Gabarre, A., Seyer, D., Bousta, F., and Di Martino, P. (2017) Bacterial diversity on rock surface of the ruined part of a French historic monument: the Chaalis abbey. Int. Biodeterior. Biodegrad. 120, 161-169. doi: 10.1016/j.ibiod.2017.02.019

Montaño-Salazar, S. M., Lizarazo-Marriaga, J., and Brandão, P. F. B. (2018). Isolation and potential biocementation of calcite precipitation inducing bacteria from colombian buildings. Curr. Microbiol. 75, 256-265. doi: 10.1007/ s00284-017-1373-0

Naether, A., Foesel, B. U., Naegele, V., Wüst, P. K., Weinert, J., Bonkowski, M., et al. (2012). Environmental factors affect acidobacterial communities below the subgroup level in grassland and forest soils. Appl. Environ. Microbiol. 78, 7398-7406. doi: 10.1128/AEM.01325-12

Nazir, R., Rehman, S., Nisa, M., and Baba, U. (2019). “Chapter 7 - Exploring bacterial diversity: from cell to sequence," in Freshwater Microbiology, eds S. A. Bandh, S. Shafi, and N. Shameem (Cambridge, MA: Academic Press), 263-306. doi: 10.1016/B978-0-12-817495-1.00007-4

Ortega-Morales, B. O., Narváez-Zapata, J. A., Schmalenberger, A., Sosa-López, A., and Tebbe, C. C. (2004). Biofilms fouling ancient limestone Mayan monuments in Uxmal, Mexico: a cultivation-independent analysis. Biofilms 1, 79-90. doi: $10.1017 /$ S1479050504001188

Pankratov, T. A., Kirsanova, L. A., Kaparullina, E. N., Kevbrin, V. V., and Dedysh, S. N. (2012). Telmatobacter bradus gen. nov., sp. nov., a cellulolytic facultative anaerobe from subdivision 1 of the Acidobacteria, and emended description of Acidobacterium capsulatum Kishimoto et al. 1991. Int. J. Syst. Evol. Microbiol. 62, 430-437. doi: 10.1099/ijs.0.029629-0

Park, S., Ym, P., Wy, C., Wj, K., and Sy, G. (2010). Calcite-forming bacteria for compressive strength improvement in mortar. J. Microbiol. Biotechnol. 20, $782-788$.

Parkes, R. J., and Sass, H. (2009). "Deep sub-surface," in Encyclopedia of Microbiology. 3rd Edn, ed. M. Schaechter (Oxford: Academic Press), 64-79. doi: 10.1016/b978-012373944-5.00275-3

Pellerin, A., Lacelle, D., Fortin, D., Clark, I. D., and Lauriol, B. (2009). Microbial diversity in endostromatolites (cf. fissure calcretes) and in the surrounding 
permafrost landscape, Haughton impact structure region, Devon Island, Canada. Astrobiology 9, 807-822. doi: 10.1089/ast.2008.0302

Piñar, G., Tafer, H., Sterflinger, K., and Pinzari, F. (2015). Amid the possible causes of a very famous foxing: molecular and microscopic insight into Leonardo da Vinci's self-portrait. Environ. Microbiol. Rep. 7, 849-859. doi: 10.1111/17582229.12313

Portillo, M. C., Saiz-Jimenez, C., and Gonzalez, J. M. (2009). Molecular characterization of total and metabolically active bacterial communities of "white colonizations" in the Altamira Cave, Spain. Res. Microbiol. 160, 41-47. doi: 10.1016/j.resmic.2008.10.002

Rodriguez-Navarro, C., Jroundi, F., and Gonzalez-Muñoz, M. T. (2015). Stone consolidation by bacterial carbonatogenesis: evaluation of in situ applications. Restor. Build. Monum. 21, 9-20. doi: 10.1515/rbm-2015-0002

Rodriguez-Navarro, C., Jroundi, F., Schiro, M., Ruiz-Agudo, E., and GonzálezMuñoz, M. T. (2012). Influence of substrate mineralogy on bacterial mineralization of calcium carbonate: implications for stone conservation. Appl. Environ. Microbiol. 78, 4017-4029. doi: 10.1128/AEM.07044-11

Rodriguez-Navarro, C., Rodriguez-Gallego, M., Chekroun, K. B., and GonzalezMuñoz, M. T. (2003). Conservation of ornamental stone by Myxococcus xanthus-induced carbonate biomineralization. Appl. Environ. Microbiol. 69, 2182-2193. doi: 10.1128/AEM.69.4.2182-2193.2003

Sassoni, E., Naidu, S., and Scherer, G. W. (2011). The use of hydroxyapatite as a new inorganic consolidant for damaged carbonate stones. J. Cult. Herit. 12, 346-355. doi: 10.1016/j.culher.2011.02.005

Schabereiter-Gurtner, C., Piñar, G., Vybiral, D., Lubitz, W., and Rölleke, S. (2001). Rubrobacter-related bacteria associated with rosy discolouration of masonry and lime wall paintings. Arch. Microbiol. 176, 347-354. doi: 10.1007/ s002030100333

Shannon, P., Markiel, A., Ozier, O., Baliga, N. S., Wang, J. T., Ramage, D., et al. (2003). Cytoscape: a software environment for integrated models of biomolecular interaction networks. Genome Res. 13, 2498-2504. doi: 10.1101/ gr.1239303

Sterflinger, K., Little, B., Pinar, G., Pinzari, F., de los Rios, A., and Gu, J. D. (2018). Future directions and challenges in biodeterioration research on historic materials and cultural properties. Int. Biodeterior. Biodegrad. 129, 10-12. doi: 10.1016/j.ibiod.2017.12.007

Sterflinger, K., and Piñar, G. (2013). Microbial deterioration of cultural heritage and works of art - tilting at windmills? Appl. Microbiol. Biotechnol. 97, 9637-9646. doi: 10.1007/s00253-013-5283-1

Valentín, N. (2010). Microorganisms in museum collections. Coalition 19, 2-5.

Videla, H. A., Guiamet, P. S., and de Saravia, S. G. (2000). Biodeterioration of Mayan archaeological sites in the Yucatan Peninsula, Mexico. Int. Biodeterior. Biodegrad. 46, 335-341. doi: 10.1016/s0964-8305(00)00106-2

Wang, J. Y., Soens, H., Verstraete, W., and De Belie, N. (2014). Self-healing concrete by use of microencapsulated bacterial spores. Cem. Concr. Res. 56, 139-152. doi: 10.1016/j.cemconres.2013.11.009

Warscheid, T. H., and Braams, J. (2000). Biodeterioration of stone: a review. Int. Biodeterior. Biodegrad. 46, 343-368. doi: 10.1016/S0964-8305(00)00109-8

Webster, D. (1999). The archaeology of Copán, Honduras. J. Archaeol. Res. 7, 1-53. doi: 10.1023/A:1022167314053

Wright, D. T., and Oren, A. (2005). Nonphotosynthetic bacteria and the formation of carbonates and evaporites through time. Geomicrobiol. J. 22, 27-53. doi: $10.1080 / 01490450590922532$

Zimmermann, J., Gonzalez, J. M., and Saiz-Jimenez, C. (2006). Epilithic biofilms in Saint Callixtus Catacombs (Rome) harbour a broad spectrum of Acidobacteria. Anton. Van Leeuwenhoek 89, 203-208. doi: 10.1007/s10482-005-9020-3

Conflict of Interest: The authors declare that the research was conducted in the absence of any commercial or financial relationships that could be construed as a potential conflict of interest.

Copyright (c) 2020 Jroundi, Elert, Ruiz-Agudo, Gonzalez-Muñoz and RodriguezNavarro. This is an open-access article distributed under the terms of the Creative Commons Attribution License (CC BY). The use, distribution or reproduction in other forums is permitted, provided the original author(s) and the copyright owner(s) are credited and that the original publication in this journal is cited, in accordance with accepted academic practice. No use, distribution or reproduction is permitted which does not comply with these terms. 